Schwendel, Arved ORCID:

https://orcid.org/0000-0003-2937-1748, Joy, Michael K., Death, Russell G. and Fuller, lan C. (2011) A macroinvertebrate index to assess stream-bed stability. Marine and Freshwater Research, 62 (1). p. 30.

Downloaded from: http://ray.yorksj.ac.uk/id/eprint/2622/

The version presented here may differ from the published version or version of record. If you intend to cite from the work you are advised to consult the publisher's version: https://doi.org/10.1071/MF10137

Research at York St John (RaY) is an institutional repository. It supports the principles of open access by making the research outputs of the University available in digital form. Copyright of the items stored in RaY reside with the authors and/or other copyright owners. Users may access full text items free of charge, and may download a copy for private study or non-commercial research. For further reuse terms, see licence terms governing individual outputs. Institutional Repository Policy Statement

\title{
RaY
}

Research at the University of York St John

For more information please contact RaY at ray@yorksj.ac.uk 


\section{Measurement of stream bed stability characteristics relevant to lotic ecosystems}

Arved C. Schwendel

Geography, College of Life and Environmental Sciences, University of Exeter, Exeter, UK A.Schwendel@exeter.ac.uk

\section{Introduction}

Climate change and anthropogenic pressure have led to significant impacts on rivers and streams in most parts of the world (Wohl, 2006; Vörösmarty et al., 2000). Changes in rainfall patterns and altered land use may affect the flow regime, catchment erosion and thus sediment supply to river systems. Human influence via damming, water abstraction and channel modification additionally impact on flow regime and sediment dynamics (Wang et $a l ., 2001)$. These alterations directly affect stream bed stability which is a key habitat parameter for lotic ecosystems (Jowett, 2003). As a response to changes in substrate stability the species composition and functionality of these ecosystems may adjust. Thus it is important for ecologists to be able to identify relevant characteristics of stream bed stability and to quantify them.

Stream bed stability is in this respect defined as the disruption of a stable state by various processes such as erosion, transport, deposition of substrate as well as abrasion by suspended or rolling particles. These processes are driven by shear forces exerted on the stream bed by flowing water and other means (e.g. fording stock or vehicles). The likelihood of natural disruption is controlled by intrinsic properties of the stream bed such as slope, imbrication of particles and substrate assemblage as well as extrinsic factors like flow regime, sediment supply or lithology.

Response of ecosystems to changing habitat conditions can be characterised in various ways, for instance by taxonomic shifts in community composition or alterations in productivity at different levels (Resh et al., 1988; Lake, 2000). However, assessment of these characteristics at an ecosystem level is laborious and thus often key groups of organisms are selected to represent the ecosystem. In lotic environments the effects of floods on substrate stability have been linked to composition of periphyton (Biggs et al., 1999), invertebrate (Cobb et al., 1992; Death and Winterbourn, 1995; Holomuzki and Biggs, 2000), bryophyte 
(Suren and Duncan, 1999) and macrophyte communities (Riis et al., 2008). However, different groups of biota respond to different characteristics of bed stability on a range of scales. For instance, sessile organisms might be affected in different ways than more mobile groups of biota (Downes, 1990; Englund, 1991; Holomuzki and Biggs, 2000; McAuliffe, 1984). Consequently, the relationship between different groups of biota and stream bed stability varies with the method employed to measure the latter (Duncan et al., 1999; Schwendel et al., 2011a). Benthic invertebrates are often employed to indicate the environmental characteristics of rivers, in particular water quality (Boothroyd and Stark 2000; Hynes 1994). Their wide range of mobility, key position in the food web, important functional role in decomposition of organic matter and high sensitivity to habitat variables on a wide range of spatial and temporal scales makes them good representatives of lotic ecosystems (Rosenberg and Resh 1993).

\section{Measurement of stream bed stability}

In order to link changes in ecosystem structure and function to habitat parameters such as substrate stability, a sensible measure needs to be identified. Schwendel et al. (2010) reviewed methods previously used to assess stream bed stability in relation to invertebrate community metrics including calculation of critical shear stress (Newbury, 1984; Cobb et al., 1992; Death and Winterbourn, 1995), FST-hemispheres (Dittrich and Schmedtje, 1995; Merigoux and Doledec, 2004), scour chains (Palmer et al., 1992; Matthaei and Townsend, 2000; Effenberger et al., 2006), scour plates (Palmer et al., 1992), tracer stones (Death and Winterbourn, 1994; Townsend et al., 1997; Death and Zimmermann, 2005; Barquin and Death, 2006), morphological budgeting (Schwendel et al., 2011a) and the Pfankuch Stability Index (Pfankuch, 1975; Death and Winterbourn, 1995; Townsend et al., 1997; Death, 2002). However, each of these methods assesses only a distinct set of bed stability characteristics and the strength of the relationship with invertebrate diversity and community composition varies (Schwendel et al., 2011a). The need of site specific calibration (e.g. bedload transport formulae and acoustics sensors) and interference with the substrate (e.g. scour plates and bedload traps) can constrain application for multi site studies and concomitant invertebrate sampling respectively (Schwendel et al., 2010). Insufficient spatial (e.g. bedload samplers) or temporal coverage (e.g. FST-hemispheres) for reach-wide, long-term bed stability assessment and potential observer bias (Pfankuch Index) can be additional problems (Schwendel et al., 2011b). 
This paper presents three approaches to measure stream bed stability characteristics that are relevant to benthic stream invertebrate communities. The first approach is an enhanced tracer technique that has been shown to be well correlated to diversity and composition of invertebrate communities (Schwendel et al., 2011a) and that also served to calibrate the other two methods. Since application of this first approach is quite time- and labour-intensive the second approach was designed to be a straightforward, time- and cost-efficient semi-visual survey with minimal instrumentation. It serves ecological studies that cannot afford elaborate measurement of each individual habitat parameter but still need at a relevant measure of stream bed stability. The third approach measures direct taxonomic response of the invertebrate community to changes in stream bed stability and other correlated habitat parameters. These approaches should provide stream ecologists and environmental authorities with the tools to assess stream bed stability and facilitate inclusion of the habitat parameter stream bed stability in more ecological studies, thus improving the understanding of habitatbiota relationships in a (variable) fluvial environment.

\section{In situ marked tracer stones}

Tracers reflect the movement of individual particles of known characteristics and thus are well suited for the stochastic and variable nature of bedload transport (Wilcock, 1997). They have been used to assess step length of movement (e.g. Habersack, 2001), proportion of the bed surface entrained (e.g. Laronne \& Duncan, 1992), transport behaviour (e.g. Gottesfeld \& Tunnicliffe, 2003) and transport rate (e.g. Ergenzinger \& Conrady, 1982), or as an indicator of bed stability (e.g. Townsend et al., 1997). However, painted tracers or other visually detected tracers (e.g. of different lithology than the natural substrate) suffer from low recovery rates as only particles on the stream bed surface can be identified (Schwendel et al., 2010). To derive meaningful results a large number of tracers needs to be employed.

Recovery rate can be improved by inserting metal bars (e.g. Schmidt \& Ergenzinger, 1992) or magnets (e.g. Ferguson \& Wathen, 1998) into the stones and using metal detectors or magnetometers respectively for relocation. However, placing tracers on the stream bed provides no information about actual bed stability and entrainment of particles because shear forces are not related to the local surface layer and properties such as embeddedness are not accounted for. In particular when the bed surface is armoured in situ marked particles may provide a better estimate of bed stability than unembedded tracers (Downes et al., 1998; Matthaei et al., 1999). 
To overcome this and the problem of low recovery Schwendel et al. (2010b) glued small-sized $(23 \mathrm{~mm}$ ) radio frequency identification (RFID) tags with the help of wet-curing epoxy concrete in situ on stones of the surface layer. This technique allows contactless detection of tracers buried under up to $0.6 \mathrm{~m}$ of gravel using a portable antenna and datalogger with an average recovery rate of 77\% (54 New Zealand streams, A. Schwendel unpublished data). Furthermore, each marked stone can be identified individually by its uniquely coded tag and thus the transported distance can be related to individual particle properties. The combination of high recovery and unique identification allows relatively low numbers of tracers to be employed (e.g. 15 per reach) which offsets the time-intensive marking process and cost of RFID tags and recovery equipment. This comparatively low number might not be sufficient to account for the full spatial variability of bedload transport in a reach but can provide a meaningful estimate of ecological relevant stream bed stability (Death and Zimmermann, 2005; Schwendel et al., 2011a). The tracer technique requires monitoring of the distance travelled by the marked stones over a certain time period whereby length and frequency of surveys depend on site characteristics (e.g. flood frequency, surface armour).

An index of bed stability derived from the mean transported distance, weighted by relative particle size, of tracers monitored over 6 months has been shown to be highly correlated with invertebrate community evenness and taxonomic richness. This is in contrast to other established techniques to assess stream bed stability such as the volume of fill derived from morphological budgeting or a flow competence calculation adapted to mountain streams (Schwendel et al., 2011a). However, the latter method could relate the percentage area of a reach subject to entrainment to bryophyte cover (Duncan et al., 1999) while the relationship with periphyton biomass is ambiguous (Biggs et al., 1999; Schwendel et al., 2011a).

The index based on tracer stones correlated very well with a distinctive axis of community composition (Schwendel et al., 2011a; 2011b) and diversity $\left(\mathrm{r}_{\mathrm{S}}=-0.54, \mathrm{df}=53\right.$, $\mathrm{p}<0.001$; Figure 1). Thus, the described tracer technique qualifies as a relevant measure of stream bed stability for invertebrate communities and in a wider sense also for lotic ecosystems.

\section{Stream bed stability survey}


Ecological studies that require a meaningful measure of stream bed stability but cannot afford regular site visits or a relative time and cost-intensive tracer technique, may apply the Stream Bed Stability for Invertebrates (SBSI) protocol (Schwendel et al., 2011b). It does not measure any single aspect of bed stability per se but determines a characteristic response of invertebrate community composition to a combination of bed stability characteristics. This distinguishes it from other approaches which aim to measure characteristics of bed stability per se but often are not very well related to responses of different groups of biota.

It was calibrated on a distinctive non-metric multidimensional scaling axis of invertebrate community composition that was highly related to stream bed stability (Schwendel et al., 2011b). Other habitat factors that may influence community composition such as physico-chemical water quality could not be entirely excluded. They were monitored and influence beyond a natural range was minimised by choosing calibration and validation sites in upland catchments with low anthropogenic impact. The SBSI survey consists of 13 parameters that cover aspects of sediment supply from banks, transport capacity and substrate erodibility as well as effects of particle transport on channel bottom structures, substrate assemblage and single grains.

The strong relationship of the SBSI score with taxonomic response to substrate disturbance enables the SBSI protocol also to predict effects on ecological characteristics of communities such as diversity (Brillouin Index) $\left(\mathrm{r}_{\mathrm{S}}=-0.69, \mathrm{df}=53, \mathrm{p}<0.001\right)$. At sites not used for its development SBSI site scores show a similar or stronger connection with community diversity metrics (Fig. 1) than more traditional bed stability measures such as in situ marked tracer stones and the bottom component of the Pfankuch Index. The latter approach is purely visual and uses only a low number of parameters for evaluation. Although correlations with metrics of lotic invertebrate and bryophyte communities have been found (Death and Winterbourn, 1995; Suren, 1996; Townsend et al., 1997; Duncan et al., 1999; Death, 2002), large differences between multiple evaluations of a stream reach within a short time by the same observer may occur due to weather and surface conditions of the substrate (wet or dry) (Schwendel et al., 2011a; 2011b). The SBSI protocol might suffer less from this problem because parameters are assessed not only visually but observer bias potentially can be a problem. Additionally, Schwendel et al. (2011b) recommend adjustments which allows the SBSI method to account for variation in particle surface constitution and angularity due to different lithologies.

In combination with the field sheet provided by Schwendel et al. (2011b) a pocket calculator and an Abney level may assist application of the SBSI protocol but are not 
obligatory. Interference with the substrate is low which facilitates concomitant sampling of biota and the stability score can be calculated on-site. Thus, this technique combines the uncomplicated application of a visual approach with the strengths of an elaborate measure of stream bed stability.

Beside scientific studies of disturbance-diversity relationships or measurement of habitat variables the SBSI protocol may be applied for efficient and ecologically relevant monitoring of human disturbance of stream beds, e.g. by gravel mining or fording. It can be also employed to assess the potentially confounding effects of bed instability on invertebrate community composition when the latter is employed to determine water quality or environmental status of a stream.

\section{Macroinvertebrate index of bed stability}

Assessment of habitat characteristics using biotic indices is common (Rosenberg and Resh 1993; Hynes 1994). In contrast to indicator species approaches where presence or abundance of individual species characterise habitat conditions, biotic community indices indicate the latter based on the composition of the entire community (every taxon scores). Community indices employ the indicator species concept without placing undue emphasis on uncommon species (Winterbourn, 1981). An index to assess stream bed stability relevant for stream macroinvertebrate communities of stony riffles (MIBS) was presented by Schwendel et al. (2011c). Although, due to endemism of taxa, its application is restricted to New Zealand the methodology is transferable to other parts of the world. The MIBS requires collection and identification of a representative invertebrate community sample for a stream reach. It measures taxonomic response to variation in substrate stability and other intercorrelated habitat variables such as periphyton biomass (Death, 2002; Schwendel et al., 2011b).

The MIBS was developed on a dataset from 46 upland streams in New Zealand's North Island. Bed stability was assessed with in situ marked tracer stones and invertebrates were sampled from riffles. After exclusion of uncommon taxa the remaining taxa underwent a Indicator Species Analysis which accounted for abundance and faithfulness of taxa to a particular bed stability class. Taxa were then arranged along the bed stability gradient according to their indicator values and assigned an index score (Schwendel et al., 2011c). The latter ranges in theory between -10, indicating unstable substrate, and 10 at stable sites. However, the lowest score assigned was -6.5 (Hydrobiosis umbripennis) because no taxon appeared to be well adapted to unstable conditions. Taxa with a low score might be tolerant 
of unstable substrate and prefer habitat characteristics or ecological conditions (such as low competition or low number of predators) common at unstable sites. Thus low bed stability is better indicated by the composition of the entire community, e.g. by absence of high scoring taxa. Under these circumstances the application of a biotic community index is of advantage (Schwendel et al., 2011c).

MIBS site scores showed a strong correlation with invertebrate community diversity $\left(r_{s}=0.54, d f=53, p<0.001\right)$. They also compare well to traditional measures of bed stability and SBSI site scores (Fig. 1) and its inclusion in the pool of variables improved modelling stream bed stability (Schwendel et al., 2011c). The MIBS score has the advantage over direct one-off measurements of bed stability that it can indicate typical habitat conditions over longer time-scales (e.g. an invertebrate life cycle) and thus encompass short-term fluctuations in bedload transport, for example as a result of variation in sediment supply from the catchment (Wathen and Hoey, 1998). Utilisation of the entire community may help assess finer gradations in bed stability, in particular at intermediate levels of substrate stability when the influence of other habitat parameters might be more pronounced (Lancaster and Downes, 2010).

Biological assessment of stream bed stability with the MIBS is particularly efficient when the invertebrate community has already been sampled for other analysis such as biological monitoring of water quality. Since many biotic indices for a habitat variable require community composition to be a function of that variable only (e.g. MCI; Stark, 1985), the MIBS can widen their applicability by assessing the confounding effects of substrate stability on community composition. However, since the MIBS was developed on a regional dataset it needs to be tested in other parts of New Zealand and, if necessary, taxon scores might need to be added or adjusted.

\section{Conclusions}

Sustainable management of rivers and their catchments requires ecologically meaningful information about habitat parameters because these play a crucial role for structure and function of lotic ecosystems. Large-scale environmental changes and human impacts may transfer to stream communities via local habitat characteristics. Substrate stability is a key factor influencing benthic communities but ecologically relevant assessment is difficult and thus neglected in many studies. This paper highlights three reach-scale approaches that are relevant and serve different requirements in terms of data collection and interpretation. 
In situ marked tracer stones are an elaborate and accurate measure of entrainment and transport of substrate particles, two characteristics of stream bed stability that are influential on lotic communities. The SBSI protocol offers a quick and efficient mean to assess a combination of bed stability characteristics specifically relevant to stream invertebrate communities. In contrast, the MIBS is a biotic community index which determines the taxonomic response of stream invertebrates to fluctuations in substrate stability.

Both, the SBSI protocol and MIBS index are calibrated on regional dataset from mountain streams and might need adjustment for application on lowland rivers and, in case of the MIBS index, also for other regions of New Zealand. Thus, I would like to encourage application of these techniques and, if necessary further development as well as the adaptation of the MIBS to other parts of the world.

\section{References}

Barquin, J. and Death, R.G. (2006). Spatial patterns of macroinvertebrate diversity in New Zealand springbrooks and rhithral streams. Journal of the North American Benthological Society, 25, 768-786.

Biggs, B.J.F., Smith, R.A. and Duncan, M.J. (1999). Velocity and sediment disturbance of periphyton in headwater streams: biomass and metabolism. Journal of the North American Benthological Society, 18, 222-241.

Boothroyd, I. and Stark, J. D. (2000). Use of invertebrates in monitoring. In: Collier, K. J. and Winterbourn, M. J. (eds.) New Zealand Stream Invertebrates: Ecology and Implications for Management. New Zealand Limnological Society, Christchurch, pp. 344-373.

Cobb, D.G., Galloway, T.D. and Flannagan, J.F. (1992). Effects of discharge and substrate stability on density and species composition of stream insects. Canadian Journal of Fisheries and Aquatic Sciences, 49, 1788-1795.

Death, R.G. (2002). Predicting invertebrate diversity from disturbance regimes in forest streams. Oikos, 97, 18-30.

Death, R.G. and Winterbourn, M.J. (1994). Environmental stability and community persistence - a multivariate perspective. Journal of the North American Benthological Society, 13, 125-139.

Death, R.G. and Winterbourn, M.J. (1995). Diversity patterns in stream benthic invertebrate communities - the influence of habitat stability. Ecology, 76, 1446-1460.

Death, R.G. and Zimmermann, E.M. (2005). Interaction between disturbance and primary productivity in determining stream invertebrate diversity. Oikos, 111, 392-402.

Dittrich, A. and Schmedtje, U. (1995). Indicating shear-stress with FST-hemispheres - effects of stream bottom topography and water depth. Freshwater Biology, 34, 107-121.

Downes, B.J. (1990). Patch dynamics and mobility of fauna in streams and other habitats. Oikos, 59, 411-413. 
Downes, B.J., Lake, P.S., Glaister, A. and Webb, J.A. (1998). Scales and frequencies of disturbances: rock size, bed packing and variation among upland streams. Freshwater Biology, 40, 625-639.

Duncan, M.J., Suren, A.M. and Brown, S.L.R. (1999). Assessment of streambed stability in steep, bouldery streams: development of a new analytical technique. Journal of the North American Benthological Society, 18, 445-456.

Effenberger, M., Sailer, G., Townsend, C.R. and Matthaei, C.D. (2006). Local disturbance history and habitat parameters influence the microdistribution of stream invertebrates. Freshwater Biology, 51, 312-332.

Englund, G. (1991). Effects of disturbance on stream moss and invertebrate community structure. Journal of the North American Benthological Society, 10, 143-153.

Ergenzinger, P. and Conrady, J. (1982). A new tracer technique for measuring bedload in natural channels. Catena, 9, 77 - 80.

Ferguson, R.I. and Wathen, S.J. (1998). Tracer-pebble movement along a concave river profile: Virtual velocity in relation to grain size and shear stress. Water Resources Research, 34, 2031-2038.

Gottesfeld, A.S. and Tunnicliffe, J. (2003). Bed load measurements with a passive magnetic induction device. In: Bogen, J., Fergus, T. and Walling, D.E. (eds.) Erosion and Sediment Transport Measurement in Rivers: Technological and Methodological Advances. International Association of Hydrological Sciences, Wallingford, pp. 211 - 221.

Habersack, H.M. (2001). Radio-tracking gravel particles in a large braided river in New Zealand: a field test of the stochastic theory of bed load transport proposed by Einstein. Hydrological Processes, 15, 377-391.

Holomuzki, J.R. and Biggs, B.J.F. (2000). Taxon-specific responses to high-flow disturbance in streams: implications for population persistence. Journal of the North American Benthological Society, 19, 670-679.

Hynes, H.B.N. (1994). Historical perspective and future direction of biological monitoring of aquatic systems. In: Loeb, S.L. and Spacie, A. (eds.) Biological Monitoring of Aquatic Systems. Lewis Publishers, Boca Raton, pp. 11-21.

Jowett, I.G. (2003). Hydraulic constraints on habitat suitability for benthic invertebrates in gravel-bed rivers. River Research and Applications, 19, 495-507.

Lake, P.S. (2000). Disturbance, patchiness, and diversity in streams. Journal of the North American Benthological Society, 19, 573-592.

Lancaster, J. and Downes, B. J. (2010). Linking the hydraulic world of individual organisms to ecological processes: Putting ecology into ecohydraulics. River Research and Applications 26, 385-403.

Laronne, J.B. and Duncan, M.J. (1992). Bedload Transport Paths and Gravel Bar Formation. In: Billi, P., Hey, R.D., Thorne, C.R. and Tacconi, P. (eds.) Dynamics of Gravel-bed Rivers. John Wiley and Sons, Chichester, pp. 177-202.

Matthaei, C.D., Peacock, K.A. and Townsend, C.R. (1999). Patchy surface stone movement during disturbance in a New Zealand stream and its potential significance for the fauna.

Limnology and Oceanography, 44, 1091-1102.

Matthaei, C.D. and Townsend, C.R. (2000). Long-term effects of local disturbance history on mobile stream invertebrates. Oecologia, 125, 119-126. 
McAuliffe, J.R. (1984). Competition for space, disturbance, and the structure of a benthic stream community. Ecology, 65, 894-908.

Merigoux, S. and Doledec, S. (2004). Hydraulic requirements of stream communities: a case study on invertebrates. Freshwater Biology, 49, 600-613.

Newbury, R.W. (1984). Hydrologic determinants of aquatic insect habitats. In: Resh, V.H. and Rosenberg, D.M. (eds.) The Ecology of Aquatic Insects. Praeger Publishers, New York, pp. 323-357.

Palmer, M.A., Bely, A.E. and Berg, K.E. (1992). Response of invertebrates to lotic disturbance - a test of the hyporheic refuge hypothesis. Oecologia, 89, 182-194.

Pfankuch, D.J. (1975). Stream reach inventory and channel stability evaluation. U.S.D.A. Forest Service, Region 1, Missoula, Montana.

Resh, V.H., Brown, A.V., Covich, A.P., Gurtz, M.E., Li, H.W., Minshall, G.W., Reice, S.R., Sheldon, A.L., Wallace, J.B. and Wissmar, R.C. (1988). The role of disturbance in stream ecology. Journal of the North American Benthological Society, 7, 433-455.

Riis, T., Suren, A.M., Clausen, B. and Sand-Jensen, K. (2008). Vegetation and flow regime in lowland streams. Freshwater Biology, 53, 1531-1543.

Rosenberg, D.M. and Resh, V.H. (1993) Introduction to freshwater biomonitoring and benthic macroinvertebrates. In: Rosenberg, D.M. and Resh, V.H. (eds.) Freshwater biomonitoring and benthic macroinvertebrates. Chapman and Hall, New York, pp. 1-9.

Schmidt, K.H. and Ergenzinger, P. (1992). Bedload entrainment, travel lengths, step lengths, rest periods - studied with passive (iron, magnetic) and active (radio) tracer techniques. Earth Surface Processes and Landforms, 17, 147-165.

Schwendel, A.C., Death, R.G. and Fuller, I.C. (2010). The assessment of shear stress and bed stability in stream ecology. Freshwater Biology, 55, 261-281.

Schwendel, A.C., Death, R.G., Fuller, I.C. and Joy, M.K. (2011a). Linking disturbance and stream invertebrate communities - how best to measure bed stability. Journal of the North American Benthological Society, 30, 11-24.

Schwendel, A.C., Death, R.G., Fuller, I.C. and Tonkin, J. (2011b). A new approach to assess bed stability relevant for invertebrate communities in upland streams. River Research and Applications. DOI: 10.1002/rra.1570

Schwendel, A.C., Joy, M.K., Death, R.G. and Fuller, I.C. (2011c). A macroinvertebrate index to assess stream-bed stability. Marine and Freshwater Research, 62, 30-37.

Stark, J.D. (1985). A Macroinvertebrate Community Index of Water Quality for Stony Streams. Water and Soil No. 87. Ministry of Works and Development, Wellington.

Suren, A.M. (1996). Bryophyte distribution patterns in relation to macro-, meso-, and microscale variables in South Island, New Zealand streams. New Zealand Journal of Marine and Freshwater Research, 30, 501-523.

Suren, A.M. and Duncan, M.J. (1999). Rolling stones and mosses: effect of substrate stability on bryophyte communities in streams. Journal of the North American Benthological Society, 18, 457-467.

Townsend, C.R., Scarsbrook, M.R. and Doledec, S. (1997). Quantifying disturbance in streams: alternative measures of disturbance in relation to macroinvertebrate species traits and species richness. Journal of the North American Benthological Society, 16, 531-544. 
Vörösmarty, C.J., Green, P., Salisbury, J. and Lammers, R.B. (2000). Global water resources: vulnerability from climate change and population growth. Science, 289, 284-288.

Wang, G.X., Li, Q., Cheng, G.D. and Shen, Y.P. (2001). Climate change and its impact on the eco-environment in the source regions of the Yangtze and Yellow Rivers in recent 40 years. Journal of Glaciology and Geocryology, 23, 346-352.

Wathen, S.J. and Hoey, T.B. (1998). Morphological controls on the downstream passage of a sediment wave in a gravel-bed stream. Earth Surface Processes and Landforms, 23, 715-730.

Wilcock, P.R. (1997). Entrainment, displacement and transport of tracer gravels. Earth Surface Processes and Landforms, 22, 1125-1138.

Winterbourn, M.J. (1981). A review of some biological methods for the assessment of water quality with special reference to New Zealand - Part 2. The use of aquatic invertebrates in studies of stream water quality. Water and Soil Technical Publication No. 22. Ministry of Works and Development, Wellington. pp. 5-16.

Wohl, E. (2006). Human impacts to mountain streams. Geomorphology, 79, 217-248.

Figure 1. Relationship between stream bed stability measured with three techniques (tracer stones (TTM), SBSI protocol and MIBS index) and benthic invertebrate community diversity (Brillouin Index). Bed stability measurements were normalised and converted to a scale where high values indicate high instability. 